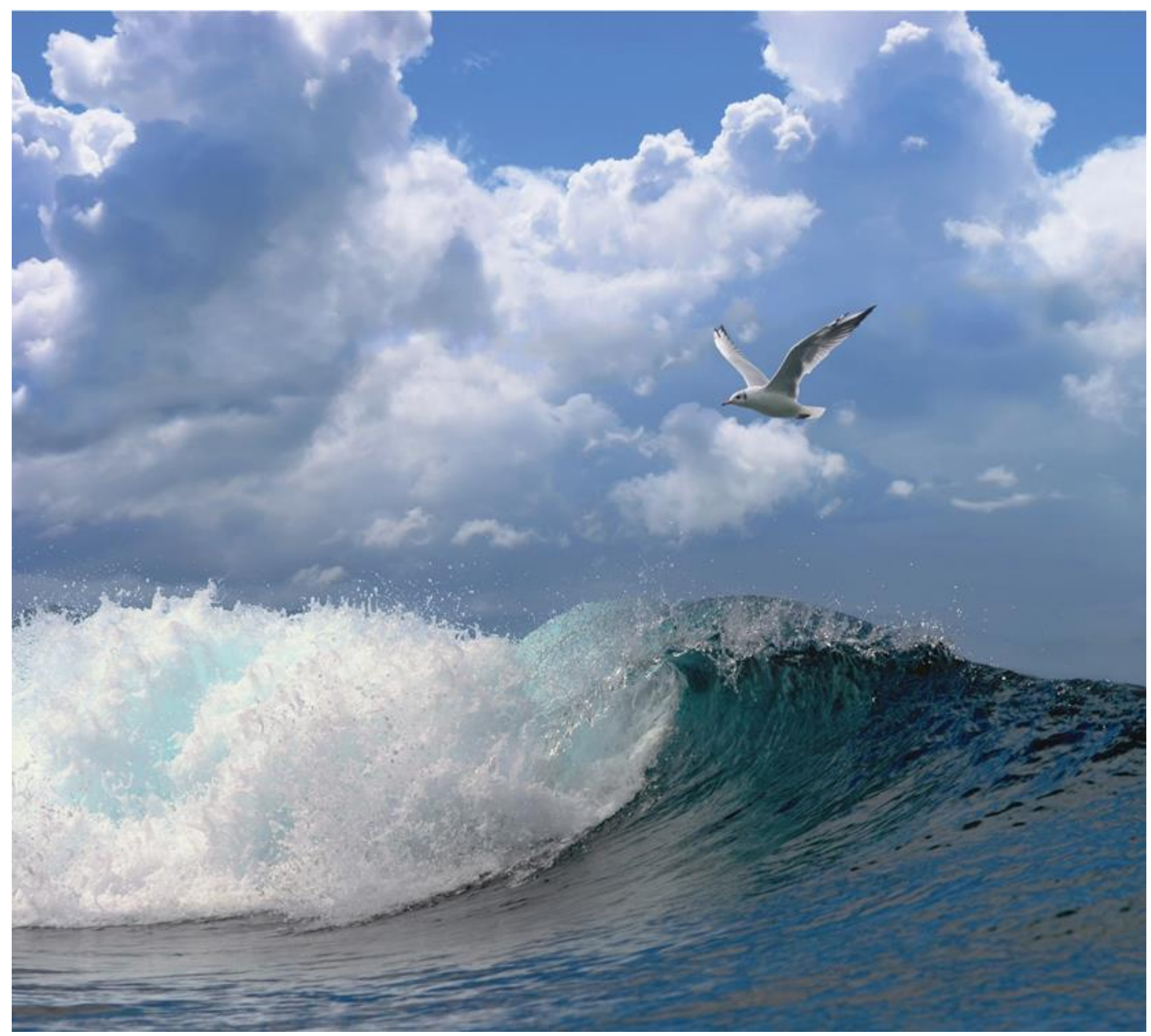

\title{
Mogelijke effecten van opening van de Haringvlietsluizen op zeehonden
}




\section{Mogelijke effecten van opening van de Haringvlietsluizen op zeehonden}

Auteur(s): Jessica Schop, Jenny Cremer, Sophie Brasseur

Publicatiedatum: 6 juni 2018

Wageningen Marine Research Den Helder, juni 2018

VERTROUWELIJK Nee

Wageningen Marine Research rapport C041/18 
J. Schop, J. Cremer, S. Brasseur, 2018. Mogelijke effecten van opening van de Haringvliets/uizen op zeehonden. Wageningen Marine Research Wageningen UR (University \& Research centre), Wageningen Marine Research rapport C041/18. 21blz.; 6 figuren tab.; 15 ref.

Keywords: zeehonden, Haringvliet, Deltawerken.

Opdrachtgever: Vereniging Natuurmonumenten

T.a.v.: Barbara Schoute

Noordereinde 60

$1243 \mathrm{JJ}$ 's Graveland

Dit rapport is gratis te downloaden van https://doi.org/10.18174/452177

Wageningen Marine Research verstrekt geen gedrukte exemplaren van rapporten.

Wageningen Marine Research Wageningen UR is ISO 9001:2008 gecertificeerd.

(C) 2016 Wageningen Marine Research Wageningen UR

Wageningen Marine Research, onderdeel van Stichting Wageningen Research KvK nr. 09098104,

IMARES BTW nr. NL 8113.83.696.B16

Code BIC/SWIFT address: RABONL2U IBAN code: NL 73 RABO 0373599285
De Directie van Wageningen Marine Research is niet aansprakelijk voor gevolgschade, noch voor schade welke voortvloeit uit toepassingen van de resultaten van werkzaamheden of andere gegevens verkregen van Wageningen Marine Research opdrachtgever vrijwaart Wageningen Marine Research van aanspraken van derden in verband met deze toepassing.

Dit rapport is vervaardigd op verzoek van de opdrachtgever hierboven aangegeven en is zijn eigendom. Niets uit dit rapport mag weergegeven en/of gepubliceerd worden, gefotokopieerd of op enige andere manier gebruikt worden zonder schriftelijke toestemming van de opdrachtgever. 


\section{Inhoud}

$1 \quad$ Inleiding $\quad 4$

2 Ontwikkeling van het aantal zeehonden in het gebied $\quad 5$

$\begin{array}{llr}3 & \text { Verspreiding van zeehonden } & 8\end{array}$

4 Scenario's voor de opening van de Haringvlietsluizen $\quad 11$

4.1 Verwachte effecten op zeehonden 12

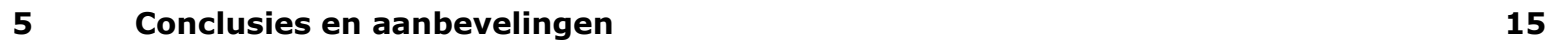

$\begin{array}{llr}5.1 & \text { Scenario's } & 15\end{array}$

$\begin{array}{ll}5.2 & \text { Aanbevelingen voor onderzoek } \\ \end{array}$

$\begin{array}{lr}\text { Literatuur } & 17\end{array}$

$\begin{array}{lr}\text { Verantwoording } & 19\end{array}$ 


\section{$1 \quad$ Inleiding}

De Deltawerken in het zuidwesten van Nederland zijn gerealiseerd naar aanleiding van de watersnoodramp in 1953. Ze bestaan uit een serie dammen en waterkeringen die het land moeten beschermen tegen overstroming in geval van zeer hoge waterstanden en storm. Bij sommige verdedigingswerken zijn estuaria afgesloten waardoor een harde overgangen van zout naar zoetwater zijn ontstaan, zo ook bij de Haringvlietsluizen.

De Haringvlietsluizen zijn geplaatst in 1970 en verbinden Voorne-Putten (noord) met GoereeOverflakkee (zuid). De sluizen bestaan uit 17 dubbele schuiven van elk $56 \mathrm{~m}$ breed. Bij een maximale opening van de schuiven ontstaat er een doorgang met een hoogte van ongeveer $6 \mathrm{~m}$. De schuiven worden tot op heden alleen geopend voor het spuien van rivierwater tijdens eb. Hoever de schuiven open gaan zijn afhankelijk van de waterafvoer van de Rijn bij Lobith en waterafvoer bij Borgharen (Maas). Door deze harde overgang van zout naar zoet water en door de vermindering van de getijdewerking, is het gebied zijn estuariënkarakter verloren. Voor transport voor schepen is er wel een doorgang doormiddel van een scheepssluis ten zuiden van de Haringvlietschuiven.

In verband met verwacht positieve effecten voor de natuurwaarden in het Haringvliet, zullen de schuiven opengezet worden om een open verbinding te vormen naar zee. Hierdoor zal het estuariumkarakter van het Haringvliet hersteld worden met een zout zoet gradiënt en wordt een mogelijkheid gecreëerd voor vismigratie. De mate van openstelling van de schuiven kan variëren. Er zijn 5 scenario's beschreven waarbij de grootte van de opening en het openingsregiem varieert (Wijsman et al. 2018). In dit rapport wordt op basis van bestaande data de verwachte effecten hiervan op de zeehonden uiteengezet.

In de Voordelta leven twee verschillende soorten zeehonden: de gewone zeehond (Phoca vitulina) en de grijze zeehond (Halichoerus grypus). Beide soorten leven en foerageren op zee, maar komen regelmatig op de kant om te rusten. Hoe vaak en hoe lang de dieren op de kant komen is afhankelijk van het individu. Tijdens de jaarlijkse verharingsperiode en geboorteperiode zijn zeehonden meer gebonden aan de locaties waar ze aan land kunnen komen.

Het aantal zeehonden dat op de kant ligt wordt bijna maandelijks geteld in het Deltagebied. In het gebied aan de zeezijde van de Haringvlietsluizen, is een aantal ligplaatsen. De zandplaat waar de meeste zeehonden worden waargenomen is de Hinderplaat (Arts et al. 2016).

Dit document bevat drie verschillende onderdelen. De beschikbare tel data en zendergegevens verzameld in het gebied voor de Haringvlietsluizen worden uiteengezet, vervolgens wordt voor elk sluisbeheer scenario een schatting gemaakt van de effecten van de opening van van de schuiven. 


\section{Ontwikkeling van het aantal zeehonden in het gebied}

Historisch was het Deltagebied belangrijk voor de gewone zeehond (Reijnders 1994). Naar verwachting werden gewone zeehonden, net als in het Waddengebied de grijze zeehonden, in de middeleeuwen uitgeroeid. Als gevolg van hevige jacht maar ook door vervuiling, verstoring en habitat destructie bij de aanleg van de Deltawerken, verdwenen de zeehonden bijna volledig uit het gebied. In navolging van het herstel van de twee soorten zeehonden in de Waddenzee (Brasseur et al. 2018, Brasseur et al. 2015) ziet men ook de aantallen zeehonden in het Deltagebied terugkomen (Figuur 1).

Zowel de gewone zeehond als de grijze zeehond zijn beschermd onder de EU-Habitatrichtlijn. De gewone zeehond is ook beschermd in het kader van de Trilaterale 'Agreement' onder de Conventie van Bonn (CMS). Hiertoe wordt de populatieontwikkeling van de dieren gemonitord en worden zo nodig beschermende beheersmaatregelen getroffen. De meeste zeehonden in Nederland leven in de Waddenzee (Figuur 1). Tellingen in de Waddenzee worden uitgevoerd door Wageningen Marine Research (WMR) in opdracht van het ministerie van Landbouw, Natuur en Voedselkwaliteit en zijn onderdeel van de Wettelijke Onderzoekstaken Natuur en Milieu. In het Deltagebied vinden zeehondentellingen plaats in opdracht van de Centrale Informatievoorziening van Rijkswaterstaat. De tellingen worden georganiseerd en verwerkt door medewerkers van het Delta Project Management. De zeehonden worden maandelijks op zandbanken tijdens laagwater geteld (Arts et al. 2016).

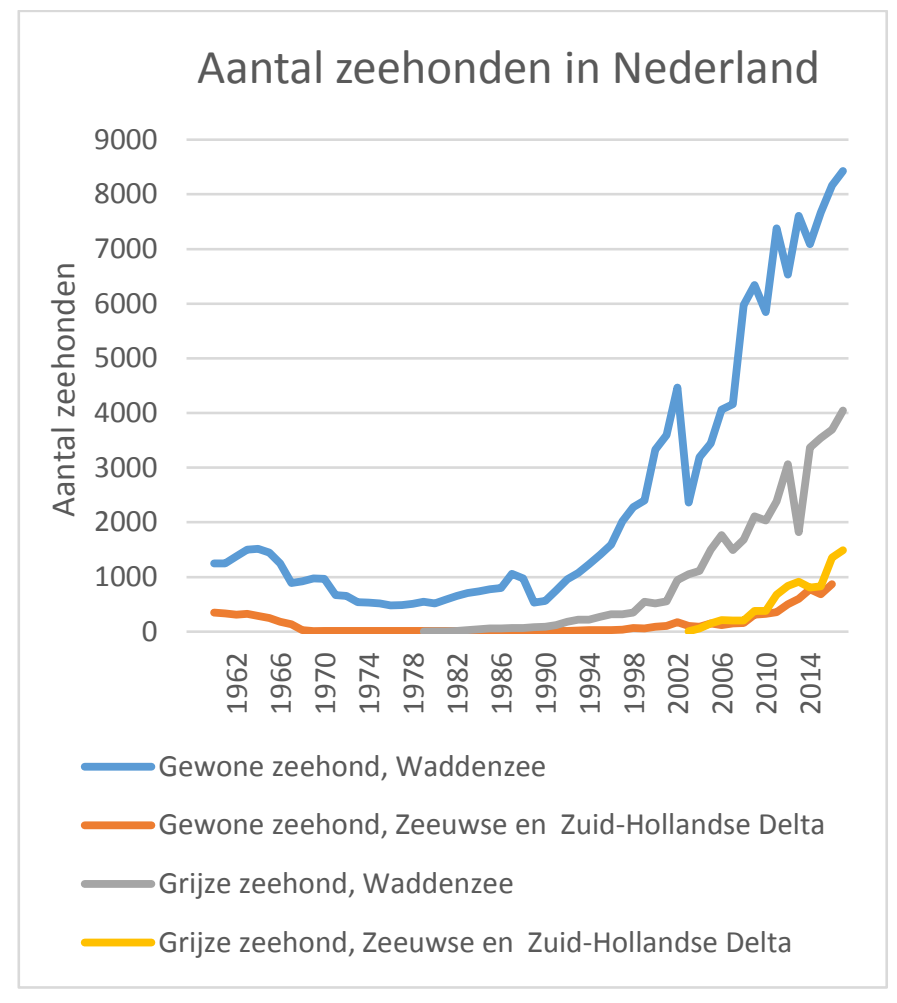

Figuur 1. Aantalsontwikkeling van gewone zeehonden en grijze zeehonden in Nederland. Bron:

http://www.clo.nl/indicatoren/nl123112

-gewone-en-grijze-zeehond-in-

waddenzee-en-deltagebied

In het gebied voor de Haringvlietsluizen (Buitendelta) maken de gewone en grijze zeehonden gebruik van verschillende zandplaten als ligplaats (Figuur 2). Deze ligplaatsen hebben de volgende benaming: Slufter en Oogeiland, Kwade Hoek (bestaande uit 'Kwade Hoek baai', 'Kwade Hoek slik' en 'Kwade Hoek tot Goeree paal 10'), Garnalenplaat en de Hinderplaat (bestaande uit 'West van de Hinderplaat' en 'Hinderplaat en water ten Oosten'). 
Het aantal zeehonden op zandbanken is niet het hele jaar door constant, maar is afhankelijk van het seizoen en de jaarcyclus van een zeehonden soort (Reijnders et al. 1995, Thompson 1989). Sinds 1990 neemt het gemiddelde aantal getelde gewone zeehonden per jaar in de Voordelta nabij het Haringvliet vrij geleidelijk toe tot aan 2013 (Figuur 3a). Het aantal getelde grijze zeehonden fluctueert in de loop der jaren meer dan het aantal gewone zeehonden, maar lijkt globaal ook toe te nemen (Figuur 3b). De maximum tellingen sinds 1990 zijn 234 gewone zeehonden (januari 2017) en 578 grijze zeehonden (mei 2015). Dit laatste lijkt uitzonderlijk, doorgaans worden er minder dan 75 grijze zeehonden in het gebied geteld.
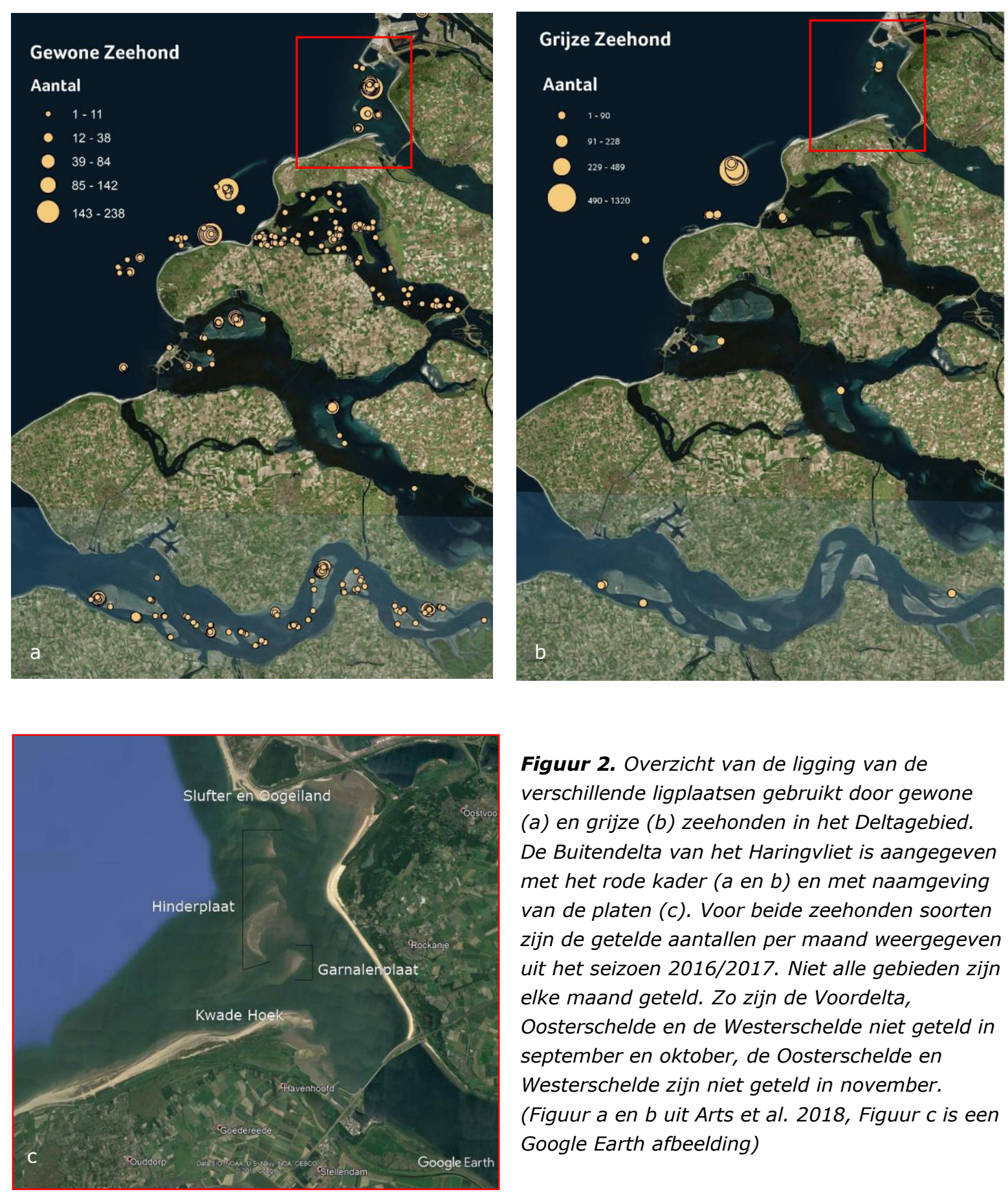

Figuur 2. Overzicht van de ligging van de verschillende ligplaatsen gebruikt door gewone (a) en grijze (b) zeehonden in het Deltagebied. De Buitendelta van het Haringvliet is aangegeven met het rode kader ( $a$ en $b$ ) en met naamgeving van de platen (c). Voor beide zeehonden soorten zijn de getelde aantallen per maand weergegeven uit het seizoen 2016/2017. Niet alle gebieden zijn elke maand geteld. Zo zijn de Voordelta, Oosterschelde en de Westerschelde niet geteld in september en oktober, de Oosterschelde en Westerschelde zijn niet geteld in november. (Figuur a en b uit Arts et al. 2018, Figuur $c$ is een Google Earth afbeelding)

Voor beide zeehondensoorten is de Hinderplaat de belangrijkste zandplaat voor de Haringvlietsluizen. Deze plaat is na de plaatsing van de Haringvlietsluizen langer en hoger gegroeid. Tevens is door de bouw van de tweede Maasvlakte in 2008-2013 de Hinderplaat afgeschermd tegen noordwestelijke golven waardoor het gebied zich heeft kunnen ontwikkelen tot een waddenachtig gebied (Elias et al., 2016). 
Bij het openen van de Haringvlietschuiven, zal de morfologie van de belangrijkste rustplaats voor zeehonden voor het Haringvliet gaan veranderen. Indien deze zandbank erodeert zullen zeehonden alternatieve rustplaatsen moeten gaan zoeken. Meer inzichten over morfologische ontwikkelingen zijn nodig om een inschatting te kunnen maken wat dit zal doen met de zeehonden in dit stukje van de Voordelta. Er is onvoldoende kennis beschikbaar om de effecten van het open van de schuiven op het totaal aantal dieren in het Deltagebied te schatten.

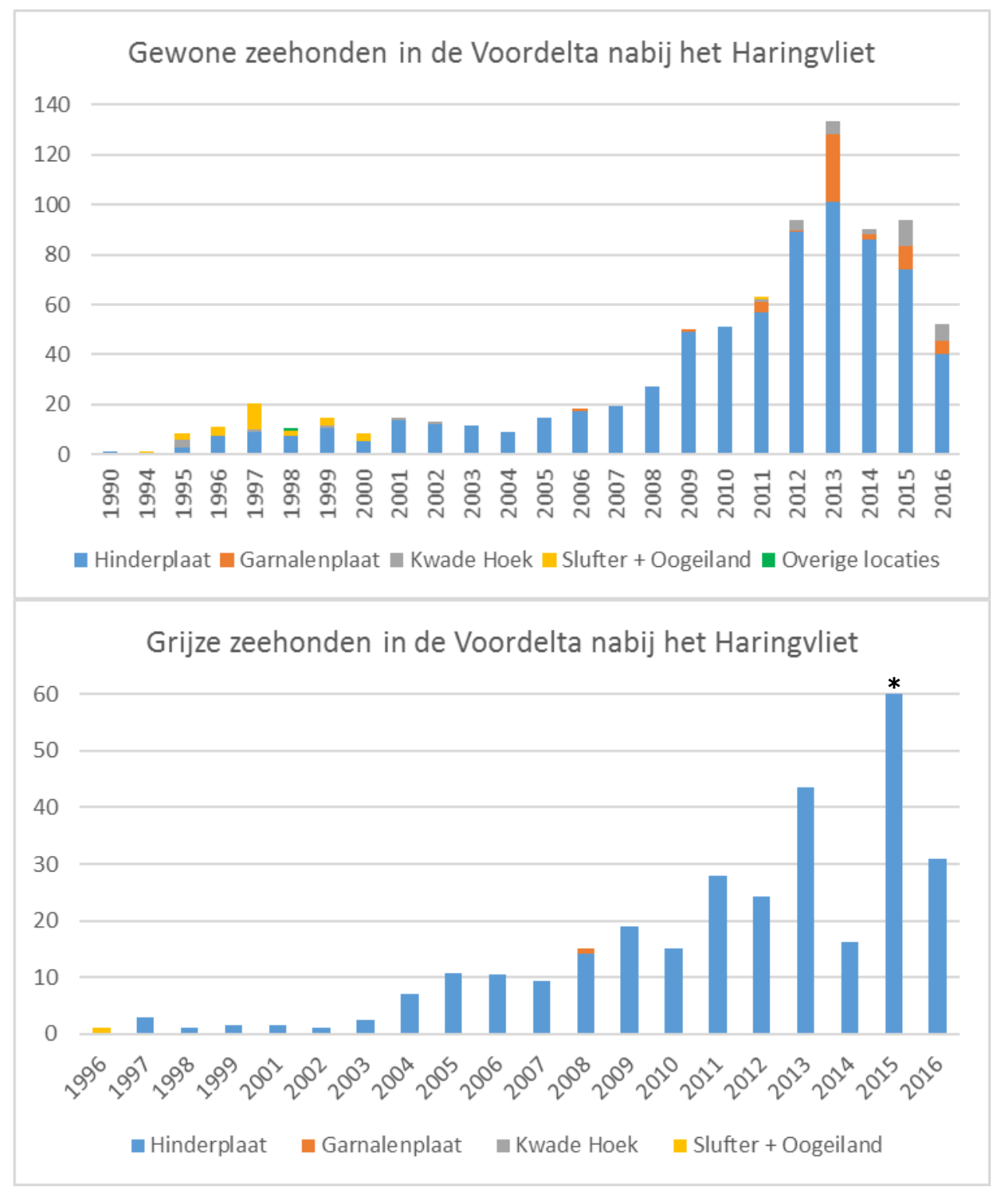

Figuur 3. Het gemiddeld aantal getelde gewone (a) en grijze (b) zeehonden per jaar in de Voordelta voor de Haringvlietsluizen. De aantallen nemen toe in de tijd. Databron: Arts et al. 2018

* in mei 2015 zijn er in de Voordelta van het Haringvliet 578 grijze zeehonden geteld, waardoor het jaargemiddelde flink hoger (113) is dan in de andere jaren. In dit jaar zijn grijze zeehonden alleen op de Hinderplaat gezien, niet op andere platen voor de Haringvlietsluizen. 


\section{$3 \quad$ Verspreiding van zeehonden}

In de periode tussen 2009 en 2017 werden in totaal 237 gewone zeehonden en 99 grijze zeehonden, op verschillende locaties in de Nederlandse Delta en Waddenzee, voorzien van een gps-zender. Dit werd gedaan in het kader van verschillende projecten van Wageningen Marine Research (WMR) met als doel het monitoren van zeehonden in relatie tot windmolenparken op zee (OWEZ: Brasseur et al. 2011, Luchterduinen: Kirkwood et al. 2014, Kirkwood et al. 2015). In dit hoofdstuk wordt aan de hand van de gps-data van de gezenderde zeehonden in het Deltagebied en de Buitendelta van het Haringvliet, een beeld geschetst van de verspreiding van beide zeehondensoorten.

Van de gezenderde zeehonden zijn GPS locaties verzameld voor de kust van Zeeland (Figuur 4 en Figuur 5). Beide soorten gebruiken het gebied voor de Haringvlietsluizen. Duidelijk is ook dat de zeehonden halfopen barrières passeren, zoals de Oosterscheldekering en de Grevenlingendam (Brasseur \& Reijnders 2001). Naar verwachting zullen zeehonden ook gebruik gaan maken van het Haringvliet wanneer deze zal worden opengesteld.

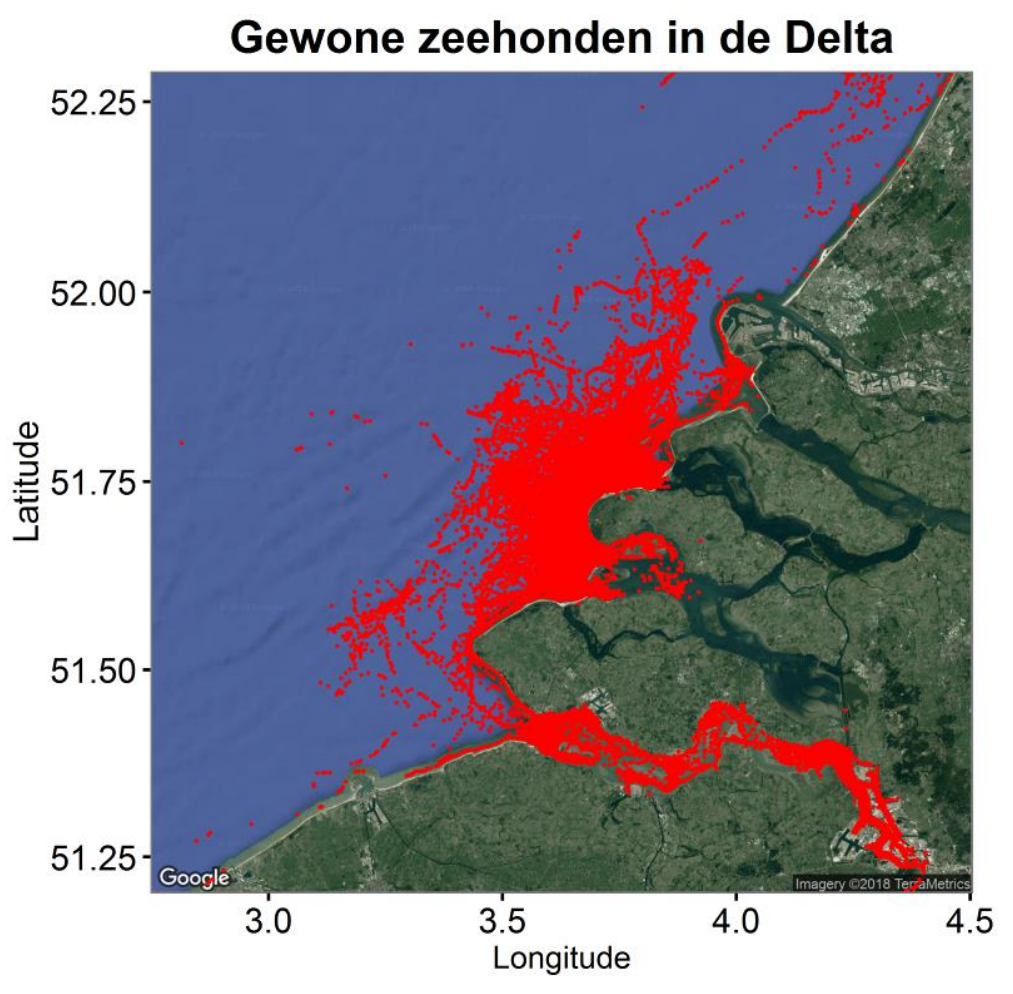

a 


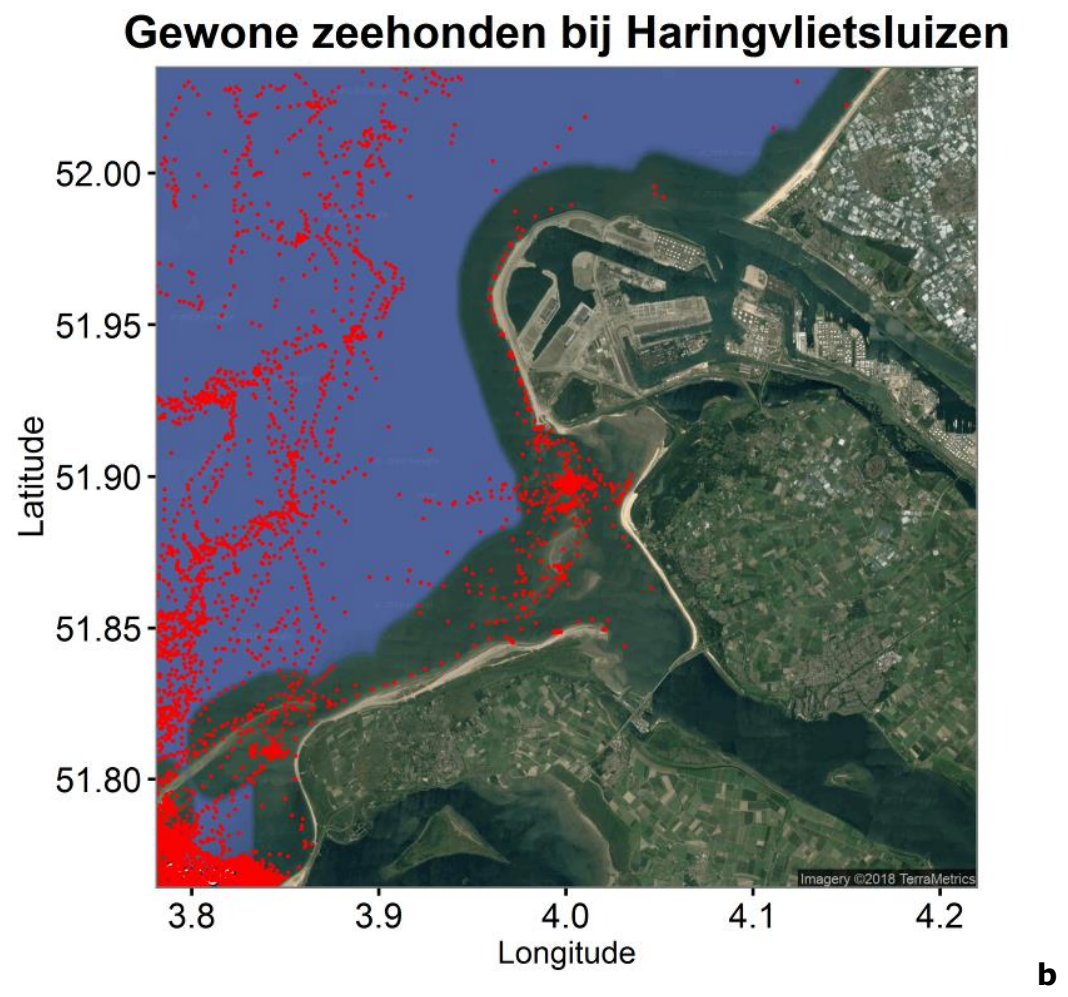

Figuur 4. Verzamelde GPS locaties door gezenderde gewone zeehonden in de Delta (a) en nabij de Haringvliets/uizen (b).

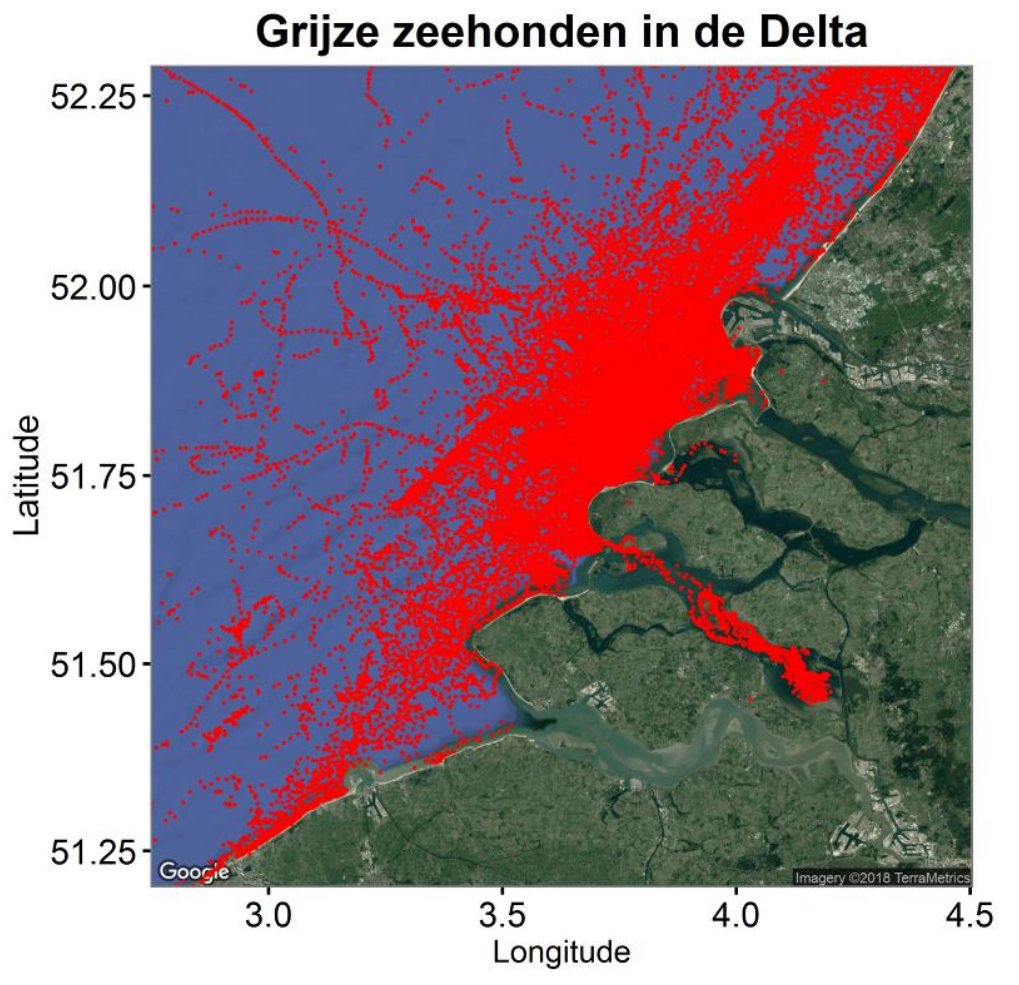

a 


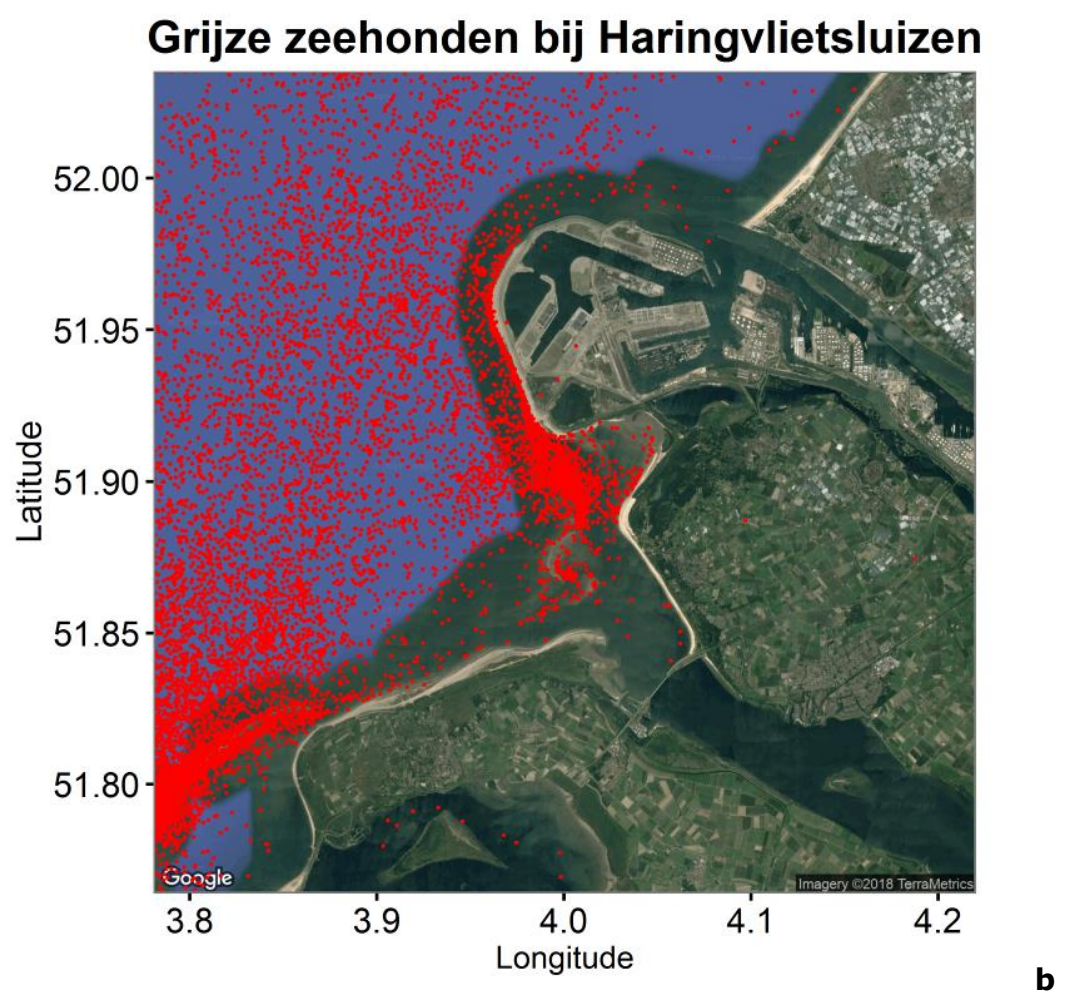

Figuur 5. Verzamelde gps-locaties door gezenderde grijze zeehonden in de Delta (a) en nabij de Haringvlietsluizen (b). 


\section{$4 \quad$ Scenario's voor de opening van de Haringvlietschuiven}

Ter voorbereiding van het besluit over de opening van het Haringvliet werden, ten oosten van de Haringvlietsluizen (Figuur 6), voor vijf scenario's de morfologische effecten gemodelleerd en zogenaamde ecotopenkaarten geschetst (Figuur 7, Wijsman et al. 2018). Effecten per scenario werden niet gemodelleerd voor de Voordelta, het gebied dat door zeehonden intensief gebruikt wordt. Op basis van de modellen van Wijsman et al. (2018) is een inschatting gemaakt wat mogelijke verandering zouden kunnen zijn voor grijze en gewone zeehonden in het gebied ten oosten van de Haringvlietsluizen. Naast een onveranderd huidig beheer, varieerden de scenario's afhankelijk van de mate en periodes waarin de schuiven worden geopend. Deze scenario's worden hieronder kort toegelicht.

\section{Huidig beheer}

In het huidig beheer worden de schuiven alleen opengezet bij eb, om rivierwater te spuien. Hoe ver de schuiven worden opgezet is afhankelijk van de hoeveelheid rivierwaterafvoer. Er is in deze situatie een beperkte getijde slag in de Haringvliet, via water dat bij de Nieuwe waterweg via het spui en Dordtsche Kil in het Haringvliet terecht komt (Figuur 6).

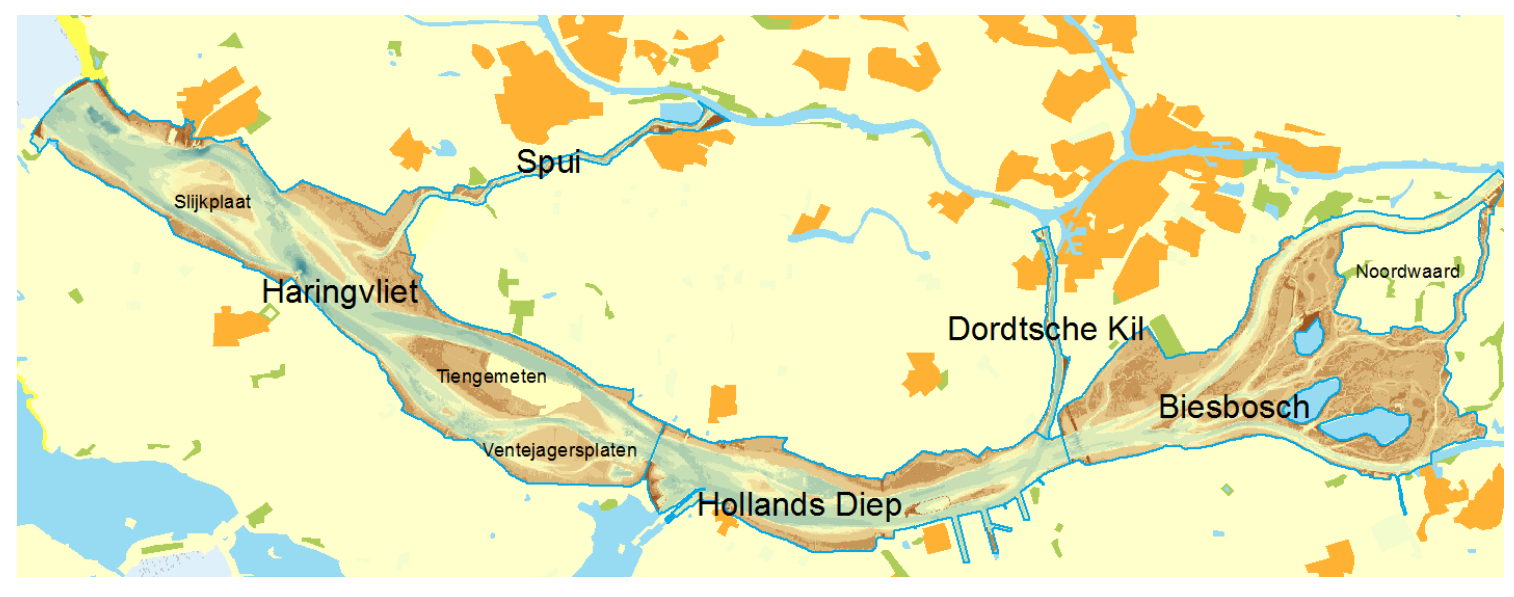

Figuur 6. Overzicht van het Haringvlietgebied (uit: Wijsman et al. 2018)

\section{Kierbesluit}

Bij het kierbesluit zullen enkele schuiven opengezet worden, zodat zout water het Haringvliet kan binnen dringen. Hiermee krijgt het Haringvliet tot aan Middelharnis een estuarium karakter. Voorbij Middelharnis zal het echter zoet gehouden worden, omdat hier zoetwater gewonnen wordt. Er worden enkele schuiven met vloed opengezet, tot een maximumhoogte van $2.45 \mathrm{~m}$, terwijl bij eb alle schuiven opgezet kunnen worden, tot een maximum opening van $\sim 6 \mathrm{~m}$ hoogte. Hoeveel schuiven en hoever ze worden opengezet is afhankelijk van twee factoren. Ten eerste is het afhankelijk van de hoeveelheid rivierwater dat aangevoerd wordt en ten tweede is het van belang dat het oosten van het Haringvliet zoet blijft. Dit kierbesluit scenario zal vanaf 2018 worden gebruikt.

\section{$80 \mathrm{~cm}$ getij}

Bij dit scenario zullen de Haringvlietschuiven continu gedeeltelijk opengezet worden. Hiermee zal een getijverschil toegelaten worden van ongeveer $80 \mathrm{~cm}$. De opening van de doorgang voor alle schuiven zal ongeveer $1.75 \mathrm{~m}$ zijn, zowel bij eb als bij vloed (Wijsman et al. 2018). 


\section{Stormvloedkering}

De schuiven zullen continu maximaal opengezet worden in de stormvloedkering variant. Hierbij zullen de schuiven opengaan tot een hoogte van ongeveer $6 \mathrm{~m}$. De schuiven worden alleen gesloten bij storm en een verhoogde zeewaterstand van +2 m NAP bij Hoek van Holland.

\section{Klimaatscenario}

Bij deze variant zal de stand van de schuiven hetzelfde zijn als bij de stormvloedkering. Voor de modellen uit Wijsman et al. (2018) is bij dit scenario echter rekening gehouden met de effecten van zeespiegelstijging. Hierbij zullen naar verwachting de schuiven vaker gesloten worden, aangezien de zeewaterstand vaker +2 m NAP bij Hoek van Holland zal bereiken.

\subsection{Verwachte effecten op zeehonden}

Zeehonden zijn in staat om smalle doorgangen te passeren. Ze passeren dergelijke doorgangen ook regelmatig naar ogenschijnlijk van de zee afgesloten wateren (Verheyen et al., 2012). Voor een deel zullen de dieren meezwemmen met sluizende schepen, echter, soms zwemmen ze door openingen zoals de duikers in de Brouwersdam. De grootte van een opening zou voor een zeehond bepalend kunnen zijn om doorheen te zwemmen. Gezien het formaat van de dieren, zal een doorgang van ongeveer $50 \mathrm{~cm}$ of kleiner naar verwachting niet vaak gepasseerd worden. Uiteraard is dit afhankelijk van de grootte van het dier waarbij volwassen grijze zeehonden beduidend groter zijn dan hun jongen of dan gewone zeehonden.

Als een zeehond eenmaal een (tijdelijke) opening in een constructie heeft kunnen passeren, is het dier afhankelijk van wanneer een opening zich weer voordoet om het openwater op te kunnen zoeken. Tot die tijd zal het moeten leren om lokaal te foerageren binnen het betreffende gebied. Daarnaast zullen de dieren rustplaatsen moeten zoeken.

\section{Huidig beheer}

Met het huidig beheer van de Haringvlietsluizen waarbij de schuiven alleen opengaan om rivierwater te spuien, wordt er incidenteel een zeehond waargenomen in het Haringvliet. De opening van de schuiven is dan echter zo dat de zeehonden naar verwachting de barrière niet kunnen passeren. De waargenomen zeehonden in het Haringvliet of ten oosten hiervan zouden daar waarschijnlijk daar terecht zijn gekomen via de scheepssluizen, ten zuiden van de schuiven. Een andere mogelijkheid zou kunnen zijn dat de zeehonden in het Haringvliet terecht zijn gekomen via een andere vaarweg, zoals de Nieuwe-Waterweg.

Met huidig beheer komen zeehonden naar verwachting in uitzondering voor in het Haringvliet of ten oosten hiervan.

\section{Kierbesluit}

Bij het kierbesluit ontstaat er een halfopen verbinding tussen de Voordelta en het Haringvliet. Dit biedt kansen voor beide zeehondensoorten. Hoe meer schuiven verder opengezet worden, des te gemakkelijker het zal zijn voor zeehonden om de Haringvlietsluizen te passeren. Met eb zouden alle schuiven opengezet kunnen worden en bij vloed zullen maximaal acht van de zeventien schuiven opengezet worden. Hierdoor zullen zeehonden meer mogelijkheden krijgen om het Haringvliet in te kunnen zwemmen.

Met het kierbesluit komen zeehonden naar verwachting incidenteel voor ten oosten van de Haringvlietsluizen. Mogelijk zullen de dieren moeite hebben terug naar zee te keren, zeker bij een lage afwatering van rivierwater. In dat geval zouden zeehonden afhankelijk van de verstoringen kunnen rusten op de Slijkplaat, ten westen van Tiengemeten en of wellicht op de Ventjagersplaten. Ook zullen de zeehonden afhankelijk zijn van lokaal aanwezige vis.

\section{$80 \mathrm{~cm}$ getij}


Alle Haringvlietschuiven zullen continu gedeeltelijk opengezet worden op een doorgangshoogte van 1,75 m (Wijsman et al. 2018). Door deze continue open verbinding met de Noordzee zullen zeehonden naar verwachting vrij het Haringvliet in en uit kunnen zwemmen. Zeehonden zitten in dit geval ook niet 'gevangen' in het Haringvliet en zouden zelf kunnen bepalen wanneer ze naar hun vertrouwde foerageergebied gaan.

Dit scenario zal in het Haringvliet een getijdenbeweging scheppen van ongeveer $80 \mathrm{~cm}$. Door deze getijdenwerking zal het gebied morfologisch veranderen en zullen zich meer potentiele rustplaatsen kunnen ontwikkelen (Wijsman et al. 2018). Zo zal de Slijkplaat in omvang toenemen. Tevens zouden de Ventjagersplaten zich kunnen ontwikkelen tot een groot intergetijdengebied en mogelijk met laagwater als rustplaats zou kunnen dienen.

Met het scenario $80 \mathrm{~cm}$ getij komen gewone en grijze zeehonden naar verwachting met regelmaat voor in het gebied ten oosten van Haringvlietsluizen. Tevens zullen de potentiele ligplaatsen in omvang toenemen. Door de continue open verbinding met de Voordelta zal er mogelijk ook meer vis kunnen uitwisselen waarop de dieren lokaal zouden kunnen foerageren.

\section{Stormvloedkering}

Bij deze variant fungeren de Haringvlietschuiven als een stormvloedkering. Alle schuiven staan continu maximaal open en hebben een doorgang van ongeveer $6 \mathrm{~m}$. Deze ruime doorgang, kan door elke zeehond relatief eenvoudig worden gepasseerd. Door de grote opening verandert de morfologie van het gebied achter de schuiven, waarbij met dit scenario mogelijk het grootste omvang aan potentiele rustplaatsen voor zeehonden zal ontwikkelen. Zowel de Slijkplaat als de Ventjagersplaten zullen toenemen in omvang (zie Wijsman et al. 2018).

Met het stormvloedkering scenario zullen zeehonden naar verwachting zich, meer als in het $80 \mathrm{~cm}$ getij scenario, gaan verspreiden in het Haringvliet en mogelijk zelfs ten oosten hiervan, zoals in het Hollandsdiep. Zeehonden zouden zich in dit geval mogelijk ook met enige regelmaat in de Biesbosch bevinden. De dieren zullen bij weinig verstoring rusten op de zandplaten in het Haringvliet. Voor het vinden van voedsel zouden ze ook relatief eenvoudig naar zee gaan kunnen gaan.

\section{Klimaatscenario}

Dit scenario lijkt op het stormvloedkering scenario, alleen is er rekening gehouden met zeespiegelstijging. De stand van de schuiven is net als bij de stormvloedkering variant volledig open en zeehonden zullen hier net zo eenvoudig doorheen migreren.

Uit modelleringen (Figuur 7) is te zien dat door een verhoogde zeespiegel het oppervlak van de Slijkplaat en de Ventjagersplaten sterk zal verminderen in vergelijking met de stormvloedkering of de $80 \mathrm{~cm}$ getij variant.

Met het klimaatscenario zullen gewone en grijze zeehonden naar verwachting regelmatig waargenomen worden ten oosten van de Haringvlietsluizen. Ze kunnen naar verwachting relatief eenvoudig de Haringvlietsluizen passeren, zowel heen als terug. Ten opzichte van het stormvloedkering scenario zal de omvang van de potentiele ligplaatsen minder groot zijn, maar groter dan bij het huidig beheer of bij het kierbesluit. 


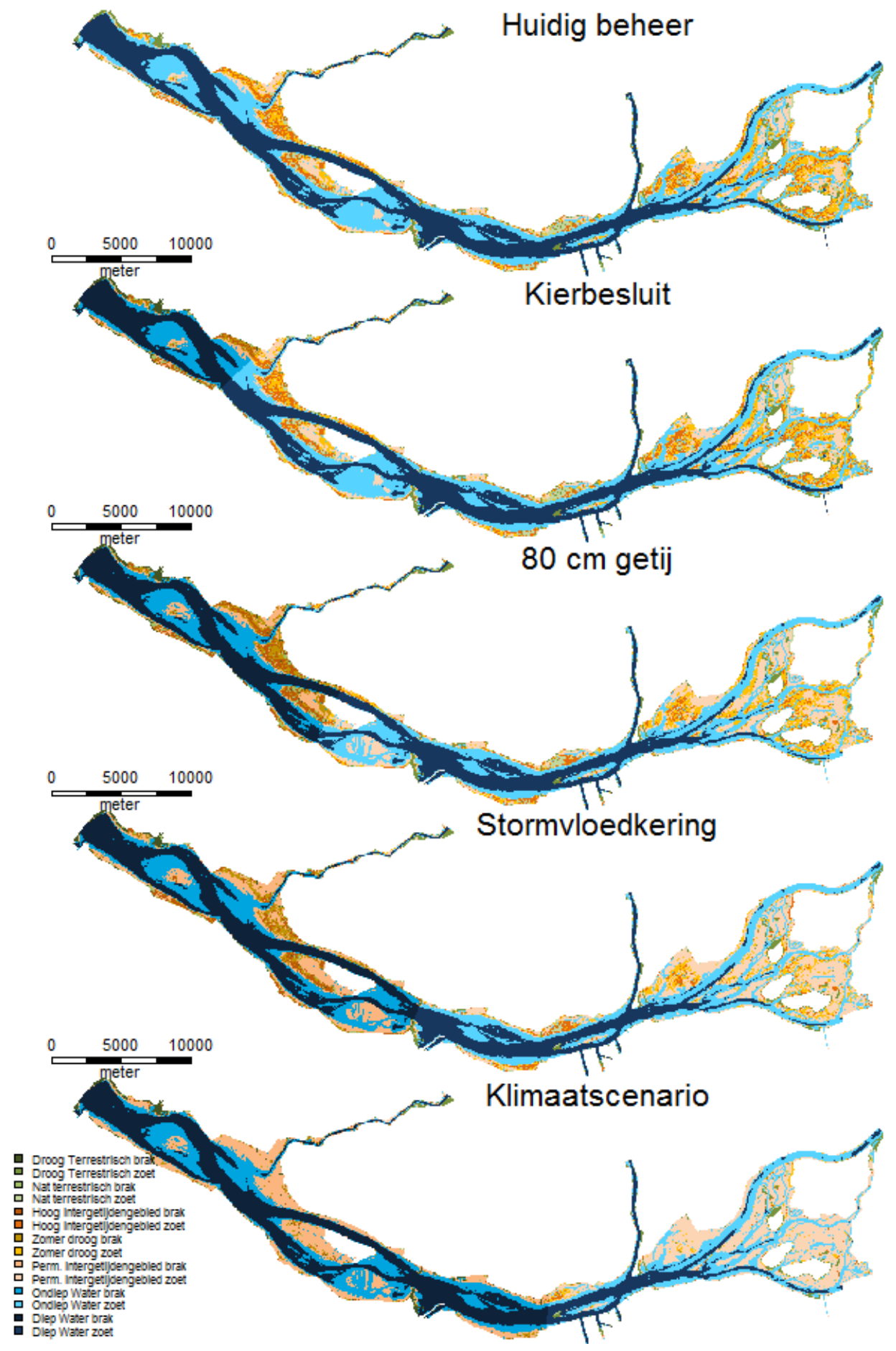

Figuur 7. Gemodelleerde ecotopen aan de hand van het huidig beheer, de scenario's kierbes/uit, $80 \mathrm{~cm}$ getij, stormvloedkering en klimaatscenario (uit: Wijsman et al. 2018) 


\section{$5 \quad$ Conclusies en aanbevelingen}

Het aantal zeehonden voor de Haringvlietsluizen is sinds 1990 toegenomen en met enige regelmaat worden er 150-200 gewone zeehonden en 10-80 grijze zeehonden aangetroffen. Bij uitzondering is in mei 2015 een grote groep van bijna 600 grijze zeehonden waargenomen. Vrijwel alle dieren worden op de Hinderplaat gezien. Naar verwachting zullen veranderingen aan de morfologie aan deze plaat gevolgen hebben voor het aantal dieren in het gebied. Potentieel heeft zo'n verandering mogelijk meer effect op de populatie dan een eventuele toename van dieren in het Haringvliet.

Zoals de zendergegevens laten zien, worden zeehonden vaker waargenomen in binnenwateren (Brasseur 2018, Verheyen et al. 2012). Zeehonden worden regelmatig waargenomen achter de half afgesloten barrières, bijvoorbeeld in het Grevelingen en de Oosterschelde. In mindere mate worden ze gezien in meer afgesloten gebieden zoals het IJsselmeer, Lauwersmeer en de spuibekkens bij Bath (https://krantenbankzeeland.nl/issue/pzc/2006-03-18). Hoe groter de opening hoe groter de kans is dat gewone en grijze zeehonden landinwaarts trekken. Hierbij is wellicht de aanwezigheid van geschikt voedsel belangrijker dan het zoutgehalte van het water. Het probleem bij meer afgesloten gebieden kan echter zijn dat het lastig is om terug te migreren, waardoor de zeehond afhankelijk is van de vis die lokaal aanwezig is. Kennis over het dieet van zeehonden is beperkt, laat staan kennis over het dieet van zeehonden in zoet water. $\mathrm{Er}$ is wel anekdotische informatie. De maaginhoud van een in het IJsselmeer gevonden dode gewone zeehond bevatte soorten vissen die in marien, brak en zoet water kunnen leven (rivierprik, Lampetra fluviatilis, bot, Platichthys flesus en spiering Osmerus eperlanus) (Verheyen et al. 2012). In 2005-2006 verbleef een zeehonden 5 maanden in een spuibekken bij Bath, ook in dit volledig zoetwateromgeving kon het dier overleven op zoetwatervis.

Zeehonden zullen een barrière met continue (half)open verbinding met zee mogelijk vaker passeren dan wanneer er een niet continu open verbinding is. Hierbij zou gelden hoe groter de opening, des te meer kans op migratie. Op deze manier migreren zeehonden geregeld door de stormvloedkering van de Oosterschelde (Brasseur \& Reijnders 2001). Om de migratie naar het Haringvliet en/of de verschillen tussen verschillende barrières in kaart te brengen is echter meer onderzoek is nodig.

\section{$5.1 \quad$ Scenario's}

Het is uitzonderlijk om een zeehond waar te nemen in het Haringvliet in het huidig beheer omdat er geen open verbinding met zee is. De enige directe migratie mogelijkheid is via de scheepssluis. Waarschijnlijk zijn er vaker zeehonden in het Haringvliet waar te nemen met het kierbesluit, waarbij er wel mogelijkheid komt om de Haringvlietschuiven te passeren.

Met eb zullen met het kierbesluit meer schuiven opengezet worden dan met vloed. Dit zou de frequentie waarmee de dieren in en uitzwemmen kunnen beïnvloeden. Als de schuiven continu open staan, zoals bij de scenario's $80 \mathrm{~cm}$ getij, stormvloedkering, en klimaatscenario, zal er naar verwachting meer uitwisseling plaatsvinden. Hierbij is te verwachten dat bij een continue maximale opening meer zeehonden het Haringvliet kunnen bezoeken, zoals bij de stormvloedkering scenario en het klimaatscenario het geval zal zijn.

Voor zeehonden is het noodzakelijk om te kunnen rusten op het droge (Brasseur et al. 1996). De beschikbaarheid van zandplaten in het Haringvliet zal daarom een rol spelen bij het gebruik van het gebied door zeehonden. De ontwikkeling van zandplaten met het $80 \mathrm{~cm}$ getij en de stormvloedkering scenario, lijkt voor de zeehonden ligplaatsen het gunstigste. In het klimaatscenario zullen zandplaten een kleinere omvang hebben en daarmee zullen er minder potentiele rustgebieden voor zeehonden zijn. Toch zal het naar verwachting meer zijn dan met het kierbesluit of het huidig beheer.

De Slijkplaat, de bank ten westen van Tiengemeten en de Ventjagersplaten, is genoemd als potentiele rustplaats voor zeehonden, maar een rustplaats voor zeehonden vereist meer factoren, waaronder 
vrijwaring van verstoring. De aanwezigheid van zeehonden op deze platen zal mede afhankelijk zijn van de beheersmaatregelen; met name het voor mensen afsluiten van gebieden zal een gunstig effect hebben.

\subsection{Aanbevelingen voor onderzoek}

Indien de Haringvlietschuiven opengaan, zal een uitbreiding van de monitoring, door het volgen van het aantal zeehonden in het Haringvliet en eventueel ten oosten hiervan, het beheer van de twee soorten vergemakkelijken. Belangrijk zal zijn hoe de aantallen zeehonden veranderen zowel binnen als buiten het Haringvliet. Zoals gezegd is een van de mogelijke zorgen een verandering van de Hinderplaat, waardoor dieren daar verdwijnen. Ook zou men kunnen overwegen om eventueel gebieden in het Haringvliet af te sluiten tegen verstoring waardoor de zeehonden zich gemakkelijker in het gebied zouden kunnen vestigen.

Meer directe monitoring van de veranderingen voor de zeehonden zou men kunnen volgen door dieren te zenderen. Aanvankelijk zou men de dieren in het gebied in de Voordelta van het Haringvliet kunnen volgen. Van de dieren die het Haringvliet inzwemmen zou bepaald kunnen worden of ze gemakkelijk hun weg terug naar zee kunnen vinden. Dit zou bijdragen aan kennis over onder andere welke schuiven door de zeehonden geprefereerd worden, waarop het sluisbeheer aangepast zou kunnen worden. Ook zou men beter kunnen anticiperen op de behoeftes van de dieren; kunnen ze in het Haringvliet foerageren? Hoe vaak gaan ze erin en eruit, waar houden de dieren zich op? Dit zijn slechts enkele vragen die met deze techniek mogelijk beantwoord kunnen worden. 


\section{Literatuur}

Arts, F.A. et al, 2018. Watervogels en zeezoogdieren in de Zoute Delta 2014/2015. RWS Centrale Informatievoorziening. Wordt afgerond

Brasseur, S.M.J.M. 2018. Stranding and Rehabilitation in Numbers: Population development and stranding data on the Dutch coasts 1990-2016; Analysis of new data from a public database. Wageningen Marine Research report C108.17.

Brasseur, S.M.J.M., J. Creuwels, B. v/d Werf, P. Reijnders. 1996. Deprivation indicates necessity for haul-out in harbor seals. Marine Mammal Science, 12(4), pp.619-624.

Brasseur, S.M.J.M. en P.J.H. Reijnders. 2001. "Zeehonden in de Oosterschelde, fase 2. Effecten van extra doorvaart door de Oliegeul." Wageningen, Alterra, Research Instituut voor de Groene Ruimte. Alterra-rapport 353.S

Brasseur, S.M.J.M., P. Reijnders, E. Meesters, G. Aarts and J. Cremer. 2011. Harbour seals, Phoca vitulina, in relation to the wind farm site OWEZ, in the Netherlands. IMARES for Noordzeewind. Report OWEZ_R_252_T1_200800303.

Brasseur, S.M.J.M., P.J.H. Reijnders, J. Cremer, E. Meesters, R. Kirkwood, L.F. Jensen, A. Je $\beta$, A. Galatius, J. Teilmann and G. Aarts. 2018. Echoes from the past: Regional variations in recovery within a harbour seal population. PLoS ONE 13:e0189674.

Brasseur, S.M.J.M., T.D. Van Polanen Petel, T. Gerrodette, E.H.W.G. Meesters, P.J.H. Reijnders and G. Aarts. 2015. Rapid recovery of Dutch grey seal colonies fueled by immigration. Marine Mammal Science 31:405-426.

Elias, E.P.L., A.J.F. Van Der Spek and M. Lazar. 2016. The 'Voordelta', the contiguous ebb-tidal deltas in the SW Netherlands: large-scale morphological changes and sediment budget 1965-2013; impacts of large-scale engineering. Netherlands Journal of Geosciences 96:233-259.

Kirkwood, R.J., G.M. Aarts and S.M.J.M. Brasseur. 2015. Seal monitoring and evaluation for the Luchterduinen offshore wind farm: 2. T-construction - 2014 report. IMARES. Report C152/14

Kirkwood, R.J., O.G. Bos and S.M.J.M. Brasseur. 2014. Seal monitoring and evaluation for the Luchterduinen offshore wind farm 1. T0 - 2013 report. IMARES. C067/14

Reijnders, P.J.H. 1994. Historical population-size of the harbor seal, Phoca vitulina, in the Delta Area, SW Netherlands. Hydrobiologia 283:557-560.

Reijnders, P.J.H., J. Van Dijk and D. Kuiper. 1995. Recolonization of the dutch Wadden Sea by the grey seal Halichoerus grypus. Biological Conservation 71:231-235.

Thompson, P.M. 1989. Seasonal changes in the distribution and composition of common seal (Phoca vitulina) haul-out groups. Journal of Zoology 217:281-294.

Verheyen, D.A.M., J.P. Verdaat, J. Ijzer, S.M.J.M. Brasseur and M.F. Leopold. 2012. Harbour seals (Phoca vitulina) in Dutch inland waters: an overview of reported sightings and some first data on diet. Lutra 55:89-99. 
Wijsman, J., V. Escaravage, Y. Huismans, A. Nolte, R.V.D. Wijk, Z.B. Wang and T. Ysebaert. 2018. Potenties voor herstel getijdenatuur in het Haringvliet, Hollands Diep en de Biesbosch. rapport c008/18. 


\section{Verantwoording}

Rapport C041/18

Projectnummer: 4311000005-20

Dit rapport is met grote zorgvuldigheid tot stand gekomen. De wetenschappelijke kwaliteit is intern getoetst door een collega-onderzoeker en het verantwoordelijk lid van het managementteam van Wageningen Marine Research

Akkoord:

Steve Geelhoed

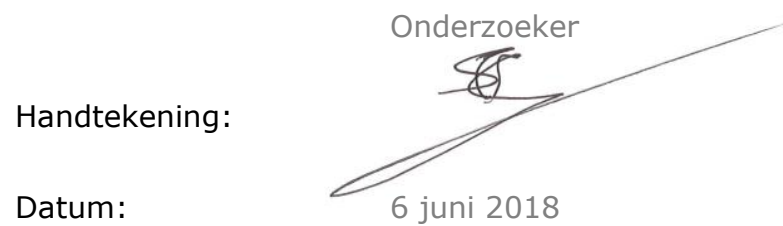

Akkoord:

Jakob Asjes

Manager Integratie

Handtekening:

Datum:

6 juni 2018 
Wageningen Marine Research

T: $+31(0) 317480900$

E: marine-research@wur.nl

www.wur.nl/marine-research

Visitors address

- Ankerpark 271781 AG Den Helder

- Korringaweg 7, 4401 NT Yerseke

- Haringkade 1, 1976 CP IJmuiden
Wageningen Marine Research is the Netherlands research institute established to provide the scientific support that is essential for developing policies and innovation in respect of the marine environment, fishery activities, aquaculture and the maritime sector.

Wageningen University \& Research is specialised in the domain of healthy food and living environment.

\section{The Wageningen Marine Research vision:}

'To explore the potential of marine nature to improve the quality of life.'

\section{The Wageningen Marine Research mission}

- To conduct research with the aim of acquiring knowledge and offering advice on the sustainable management and use of marine and coastal areas.

- Wageningen Marine Research is an independent, leading scientific research institute.

Wageningen Marine Research is part of the international knowledge organisation Wageningen UR (University \& Research centre). Within Wageningen UR, nine specialised research institutes of Stichting Wageningen Research (a Foundation) have joined forces with Wageningen University to help answer the most important questions in the domain of healthy food and living environment. 